\title{
4-Vinyl-1-cyclohexene Diepoxide
}

National Cancer Institute

\section{Source}

National Cancer Institute. 4-Vinyl-1-cyclohexene Diepoxide. NCI Thesaurus. Code C44326.

A synthetic, colorless liquid that is soluble in water. It is used as a reactive diluent for other epoxides and as a monomer in the production of epoxy resins for coatings and adhesives. Occupational exposure of humans to 4-vinyl-1-cyclohexene diepoxide results in skin irritation. It is reasonably anticipated to be a human carcinogen. ( $\mathrm{NCl05})$ 